\title{
EXPERIMENTAL APPROACH FOR EVALUATION OF ANISOTROPY IN EXTRUDED UNDERFRAME PART OF HIGH SPEED TRAIN
}

\author{
C.H. Lee ${ }^{1}$, J.C. Park, S.Y. Lee, J.S. Cho, J.Y. Song and J.H. Kim \\ ${ }^{1}$ Reliability Assessment Department, RIST, chlee@rist.re.kr
}

\begin{abstract}
Nowadays, extruded aluminum part is widely used for high speed train because it helps to enhance the light weight with relatively high strength. In this research, the extruded underframe part of the high speed train (Fig.1) is investigated considering the anisotropy issue with respect to its extrusion direction that is evolved during the extrusion process. In order to figure out the anisotropic characteristics, experimental approach based on the uniaxial tensile tests is proposed to evaluate the anisotropy of the extruded part, and, the directionality is analyzed by the deformation-induced anisotropy during the extrusion process considering the process characteristics. Moreover, the extruded part has the several numbers of seam line because it is produced by porthole die extrusion, so, the effect of seam line is also considered.
\end{abstract}

\section{INTRODUCTION}

In recent years, environmental issues play a key role to determine the direction of technology development. Following that mood, one of the most important issues in the railroad transportation industry is eco-friendliness of vehicle include considering the energy efficiency. In order to enhance the energy efficiency of the vehicle, extruded aluminum part is widely used for high speed train because it helps to enhance the light weight with relatively high strength.

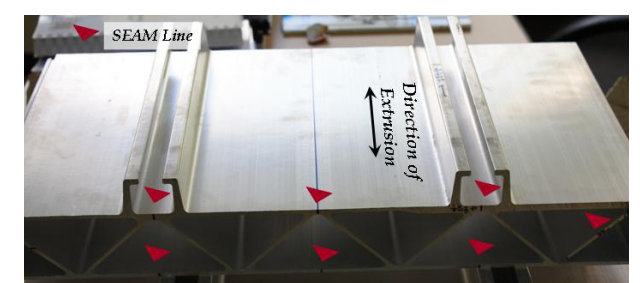

Fig.1 Picture of the extruded underframe part

In this research, the extruded underframe part of the high speed train is investigated considering the anisotropy issue with respect to its extrusion direction that is evolved during the extrusion process. The extruded underframe part usually has the structural reinforcement to overcome the severe and periodic load condition in a certain lifetime. Therefore, the structural stability and uniform deformation of the underframe part is very important to enhance their reliability by reducing the distortion of the body. Moreover, the analyzed anisotropic characteristics can be applied to optimization of the structural reinforcement of the extruded part.

\section{EXPERIMENTAL APPROACH}

The method of examination of material anisotropy has two major branches; one is a macroscopic method using a specimen test such as uniaxial tension or compression test, and another is microscopic observation of material properties, using orientation distribution function (ODF), pole figure. In this research, in order to figure out the directional characteristics, experimental approach based on the uniaxial tensile tests is proposed to evaluate the anisotropy of the extruded part, and, the directionality is analyzed by the deformation-induced anisotropy during the extrusion process considering the process characteristics. Moreover, the extruded part has the several numbers of seam line because it is produced by porthole die extrusion, so, the effect of seam line is also considered.

From the uniaxial tensile tests, it can be obtained the material parameter of the part such as tensile strength, yield strength and elongation, and, those parameters have different values with respect to its direction. In this research, the directional angle is defined by the angle from the extrusion direction, so, $0^{\circ}$ means the extrusion direction and $90^{\circ}$ means the transverse direction.

Fig.2 shows the specimen geometry with ASTM B 557B standard, and Fig. 3 shows the type of the specimen to analyze the directional characteristics. Furthermore, the geometric $r$-value ${ }^{[1]}$ is obtained from the experiment, and, the geometric $r$-value $\left(r_{g}\right)$ can be calculated by the equation (1). In the equation, $w$ and $t$ means the width and thickness, and, $i$ and $f$ means the initial and final geometry of the specimen. In addition to that, those

Dr. Chang-Hui Lee

Reliability Assessment Department, RIST

\#32 Hyoja-Dong, Nam-Gu, Pohang City, 790-330, Gyeongbuk, KOREA(S)

Tel: (+82)54-279-6227, Fax: (+82)54-279-6459

E-mail: chlee@rist.re.kr 
parameters are compared with respect to the absence of the seam line.

$$
r_{g}=\frac{\ln \left(w_{f} / w_{0}\right)}{\ln \left(t_{f} / t_{0}\right)}
$$

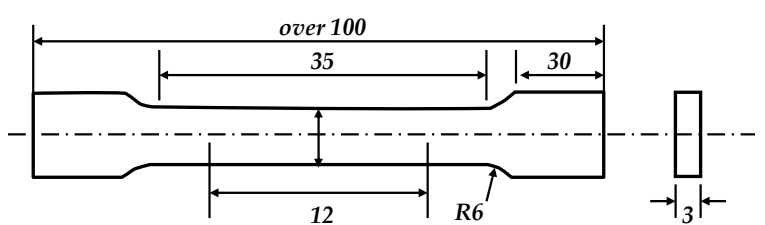

Fig.2 Dimension of Specimen (ASTM B 557M-Sub-size, unit:mm)

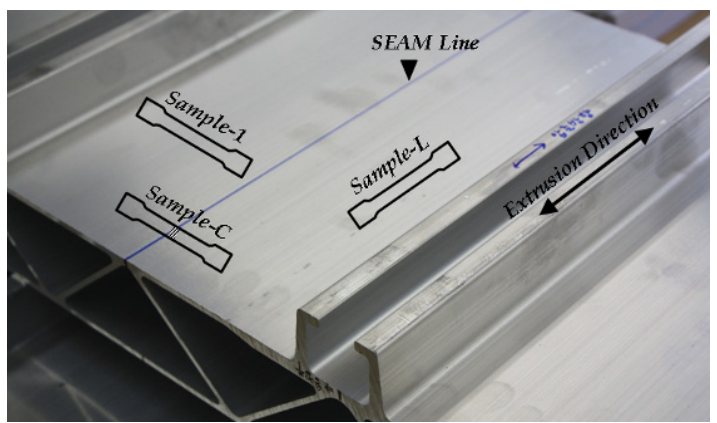

Fig.3 Location of specimen for tensile test considering extrusion direction

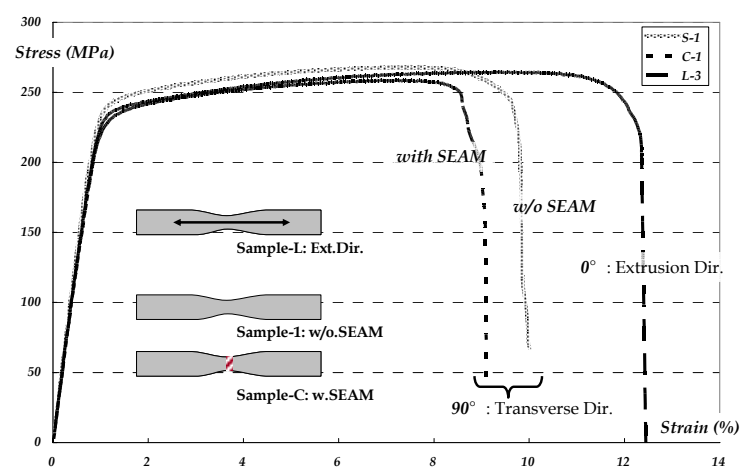

Fig.4 Representative Stress-Strain curve considering directionality

Table 1 Test result of the extruded part

\begin{tabular}{l|c|c|c|c}
\multirow{2}{*}{} & $\begin{array}{c}\text { Stress At } \\
\text { Offset Yield }\end{array}$ & Peak Stress & Break Stress & $\begin{array}{c}\text { Strain At } \\
\text { Break }\end{array}$ \\
\cline { 2 - 5 } & $\mathrm{MPa}$ & $\mathrm{MPa}$ & $\mathrm{MPa}$ & $\%$ \\
\hline \hline $0^{\circ}$ (E.D.) & 231.27 & 264.04 & 204.66 & 12.50 \\
\hline $45^{\circ}$ & 168.37 & 203.19 & 113.87 & 11.70 \\
\hline $90^{\circ}$ (w/o SEAM) & 238.22 & 268.76 & 208.47 & 9.78 \\
\hline $90^{\circ}$ (w. SEAM) & 224.31 & 255.71 & 162.13 & 8.80 \\
\hline
\end{tabular}

Fig. 4 shows the representative stress-strain curve from the preliminary test. The sample- 1 and $C$ with transverse direction show the higher tensile strength and yield stress than the sample-L with extrusion direction, but, the elongation of the sample- 1 and $C$ are lower than the sample-L. The $r_{g}$-value is slightly higher in sample-L, and, it needs further discussion after the additional experiment. After the analysis, it is expected to characterize the directional anisotropy of the extruded underframe part, and, it can be applied to the design optimization of the product with enhanced capability.

\section{THEORETICAL APPROACH}

To analyze the experimental results, the prediction of material anisotropy due to plastic deformation must be considered. In the metal forming processes such as extrusion, drawing, and forging etc, plastic deformation is one of the major causes for change in mechanical properties. From the deformation process, orientation of slip systems is rearranged with preferred orientations, i.e., deformation texture.
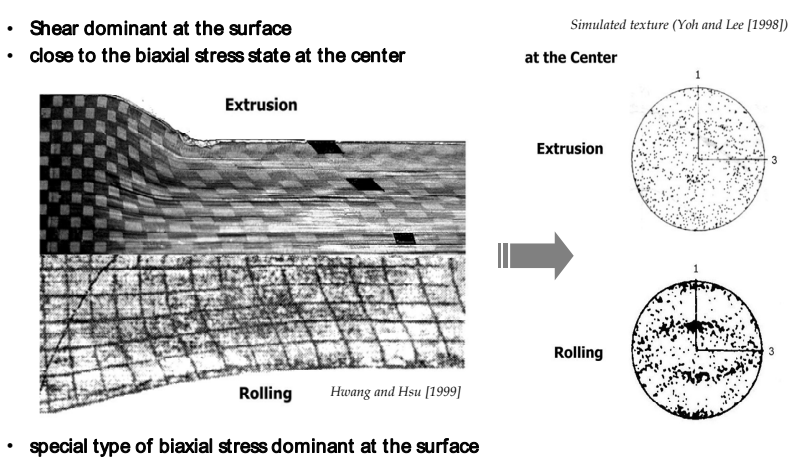

Fig.5 Comparison of deformation textures due to plastic deformation with various process

In order to analyze the material anisotropy using finite element analysis, anisotropy is usually interpreted as the material constitutive relations. Therefore, the present study compares the result with experimental approach and simulative approach using prediction algorithm to interpret the deformation-induced anisotropy.

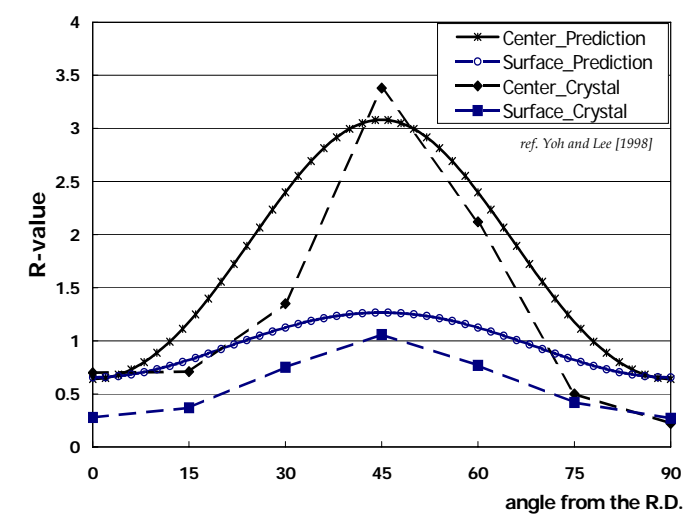

Fig.6 Comparison of analysis of deformation-induced anisotropy with crystallographic texture analysis and FE-simulation 


\section{ANALYSIS OF THE RESULTS}

In this chapter, the test result is compared and analyzed with previous researches. After the comparison with in-depth discussion, the further direction of research to modify the current result can be suggested.

\subsection{Previous Approach}

From the previous experimental ${ }^{[1],[2]}$ and theoretical research ${ }^{[3],[4]}$, the directionality of the extruded tube of Al-alloys can be compared. In Fig.7, the experimental results of the extruded square tube are demonstrated. From the experiment, the R-value and the yield stress of the square tube is varied with the angle from extrusion direction. It means that the directional anisotropy is existed in the extruded square tube with AlMgZn alloy ${ }^{[2]}$, and it can affect the material property and its formability in the proceed process.
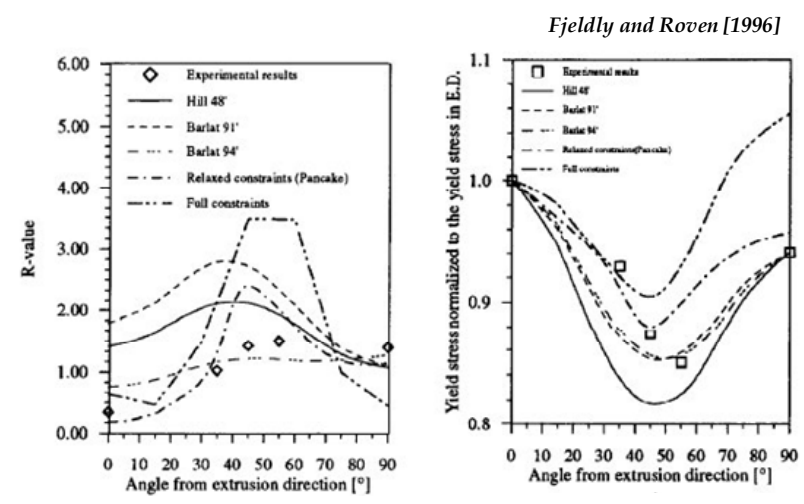

Fig.7 The experimental result of deformation-induced anisotropy in the square tube $\mathrm{e}^{[2]}$

Furthermore, Fig. 8 shows the simulative distribution of the anisotropic properties as the result of the prediction of deformation-induced anisotropy considering the phenomenological yield function ${ }^{[3]}$.

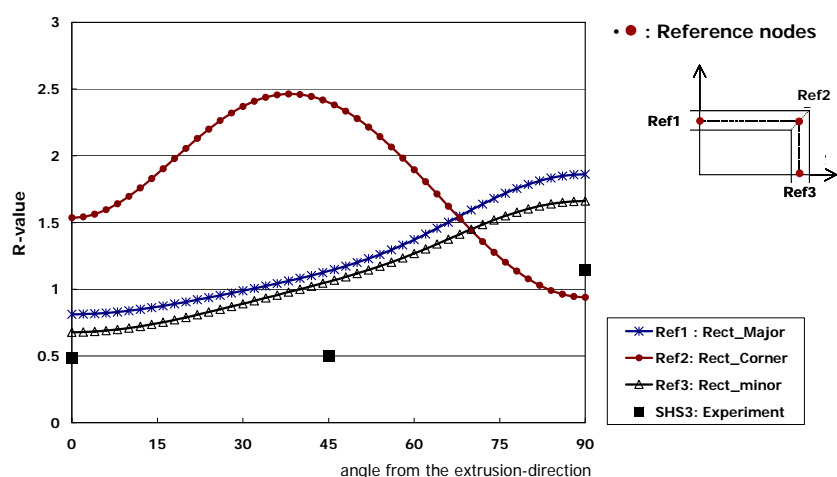

Fig.8 Predicted R-value distribution in the extruded rectangular tube ${ }^{[4]}$

\subsection{Test results of the Extruded Underframe Parts}

From the tensile test of the extruded underframe part, the material anisotropy can be evaluated by the distribution of R-value and the yield stress with the same way of previous research.

Table2 shows the R-value of the part. It shows that the $\mathrm{R}$-value in the 45 degree from the direction of the extrusion is the maximum and its value is about 1.02 . This result is different from the previous research. Therefore, the difference should be discussed with further research.

Moreover, the R45 is about 2 times higher than R0, and it means that the formability in 45-direction is better than the others. Furthermore, the SEAM line is hardly affected to the material properties.

Table2. R-value of the extruded underframe

\begin{tabular}{c|c|c|c|c|c}
\hline \multicolumn{2}{c|}{} & Sample1 & Sample2 & Sample3 & Average \\
\hline \hline \multirow{3}{*}{ w/o SEAM } & 0 도 & 0.51 & 0.56 & 0.48 & 0.52 \\
\cline { 2 - 6 } & 45 도 & 1.18 & 0.75 & 1.15 & 1.02 \\
\cline { 2 - 6 } & 90 도 & 0.37 & 0.58 & 0.39 & 0.45 \\
\hline with SEAM & 90 도 & 0.60 & 0.42 & 0.65 & 0.56 \\
\hline
\end{tabular}

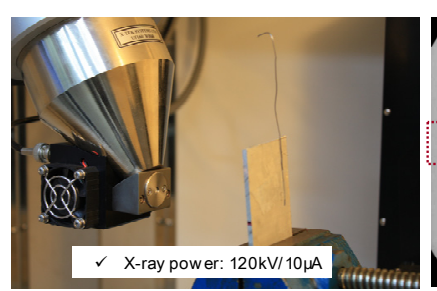

Fig.9 Non-destructive observation of the SEAM line

From Fig.9, it can be explained the less effect of SEAM line in the underframe part. From the X-ray observation of the extruded part, there is no difference in matrix and the SEAM line. It means that the material is completely welded from the porthole die extrusion without any kind of inferiorities for the product quality.

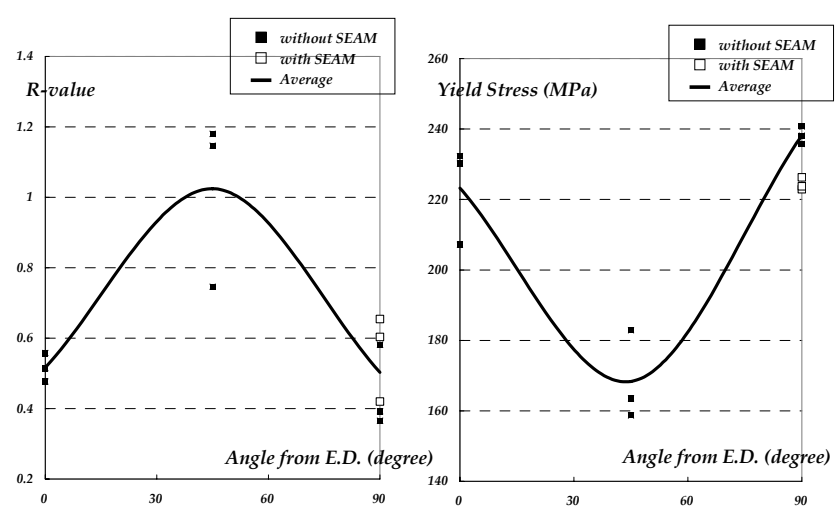

Fig.10 Directionality of the extruded underframe based on distribution of R-value and yield stress 
As the result, it is concluded that the directionality is existed in the extruded underframe part from the severe and complicated deformation from the extrusion process. In Fig. 10, the existed directionality is easily observed from the distribution of R-value and yield stress in the direction of extrusion.

\section{CONCLUSION AND FURTHER STUDY}

The directional characteristic plays a key role for the reliability of the vehicle under the periodic stress condition in the industrial use. Therefore, the in-depth research for the directionality and anisotropic characteristics should be considered more precisely.

In this research, the existence of the directionality is clearly observed from the experiment. However, the analysis considering the deformation-induced textures is insufficient. In further study, the more consideration for the directional characteristics of the vehicle must take place for the reliable vehicle design.

\section{REFERENCES}

[1] Tryland, T., Hopperstad, Odd S., Langseth, M.: Design of experiments to identify material properties, Materials \& Design, Vol.21, 477-492 (2000).

[2] Fjeldly, A and Roven, H.J.: Observations and calculations on mechanical anisotropy and plastic flow of an AlZnMg extrusion, Acta Metallurgica, Vol.44 (No.6), 3497-3504 (1996)

[3] Lee, C.H., Yang, D.Y., and Lee, Y.-S.: Verification of the prediction of deformation-induced anisotropy for simple deformation modes: uniaxial state and pure shear state of stress, Materials Science and Engineering A, Vol.339, 302-311 (2003)

[4] Lee,C.H, Yang, D.Y., and Barlat, F.: Finite element prediction of deformation-induced anisotropy in profile extrusion of aluminum alloy, Proc. of the 7th Int'l Conf. on Numerical Methods in Industrial Forming Processes-NUMIFORM2001, 433-438 (2001) 